\title{
A Game-Theoretic Model of Private Power Production
}

\author{
Weiguo Xing Felix F. Wu, Fellow, IEEE \\ Center for Electrical Energy Systems \\ Dept. of Electrical \& Electronic Engineering \\ The University of Hong Kong \\ Hong Kong SAR
}

\begin{abstract}
Private power production has sprung up all around the world, especially in developing countries with rapidly increasing demands and shortage of finance. BOT arrangements have emerged as one of the most important options of private power production. Based on oligopoly theory, this paper proposes a Stackelberg game model between a BOT company and a utility where they negotiate a long-term energy contract. It is assumed that a host utility purchases electricity from a BOT company at its "avoided cost", and sells its electricity to end users at its average cost. Taking asymmetric pricing into account, our Stackelberg game model is transferred into a two-level optimization problem, and is then solved by an iterative algorithm.
\end{abstract}

Keywords: Private power production, Build-OperateTransfer, Game theory, Two-level optimization.

\section{INTRODUCTION}

A large amount of private power production has emerged as worldwide electrical power industry entering into a new era due to deregulation. Rapid demand growth and shortage of financial investment from governments, private power production is encouraged into the traditionally monopolistic power industries in developing countries, among which BOT arrangement is becoming the most popular option, such as the $700 \mathrm{MW}$ Shajiao-B power stations in China, 1200MW Hab River project in Pakistan, $300 \mathrm{MW}$ coal-fired projects in Philippines and $1000 \mathrm{MW}$ Aliaga project in Turkey $[1,2,3]$.

A BOT arrangement is one where a consortium of private companies to finance, build, operate an infrastructure project for a relative long specific period, and at the end of this concessionary period, when it has been estimated all investment costs have been recouped and a profit returned, transfer the project title from the private consortium to the host. The long term nature of BOT arrangement gives rise to concerns of many kinds of future uncertainties which face BOT investors and the host with risks [5]. To mitigate risks, BOT investors usually ask for an important contract, "energy contract", which stipulates how much energy of the BOT power plant is to be delivered, at what price and during what time periods [4]. In an energy contract, a minimal annual energy of the BOT power plant must be guarantee for delivery, by which the fixed investment cost and operating cost of a BOT power plant will be paid back. However, in the meantime the utility will lose dispatchability of the BOT power plant.
In this paper a fixed amount of annual energy and a fixed energy price of a BOT Power plant are assumed, and from the point of view of oligopoly theory, a Stackelberg game model is proposed to describe the interaction between a BOT investor and a host utility in an energy contract negotiation. In addition, asymmetric pricing schemes are taken into account, where the host utility purchases electricity from the BOT power plant at a rate of "avoided cost" but sells its electricity to the end users at itself average cost. In fact, if both the BOT power plant and the host utility sell their electricity at their respective marginal costs, the social welfare optimal will be reached at the same time. Different pricing schemes make this bargaining more complicated.

Game theory is a discipline that is used to analyze problems of conflict among interacting decision makers. Game theory has already been used for the analysis of electricity pricing and bargaining $[6,7,8,9,10,11]$ in recent years. For example, J. Ruusunen, etc [6], applied cooperative game theory to analyze electricity exchange in a power pool, and a two-level hierarchical algorithm was proposed to solve the problem. A. Haurie, etc [7], modeled the interaction between a utility company and electricity cogenerators via a game theoretic, systems analysis approach, and a bilevel optimization technique was developed to compute the equilibrium.

In the applications of game theory, recently oligopoly theory has been applied more and more because it has been realized that power markets are not perfect competitive more than oligopolistic markets. Obviously the game between a BOT investor and a host utility is a very case where the utility owns a leadership and a BOT power plant is a price taker.

In addition, most of electricity pricing and bargaining models in literature mainly focused on real-time operation, and then discussed game players' behaviors. The BOT arrangement is quit different, the model and analysis must involve long-term affects on the operation and planning of a power system. Therefore in our game model Long-term generation expansion planning (GEP) is adopted as a suitable tool to evaluate a BOT arrangement [4].

The remainder of the paper is arranged as follows: In Section II the game model is presented. In Section III the game model is transferred to a two-level optimization problem. In Section IV an iterative algorithm is developed to solve this optimization problem. In Section V the game model is applied to an illustrative example, and some analyses are conducted. Section VI concludes the paper. 


\section{ENERGY CONTRACT AND GAME MODEL}

Criticisms are often raised on BOT projects in developing countries, after the project is in operation, on its high electricity prices and/or annual energy outputs that are agreed by host utilities, and the effects of a BOT energy contract on long-term system scheduling and planning. Therefore, a rational decision-support model that can be used to analyze the efficiency of the contract is needed. In this paper, oligopoly theory is used for the negotiation and bargaining of a BOT energy contract.

We use a simplified model that involvers a single-BOT power plant and a single-utility. An energy contract between the two is needed to negotiate. The BOT power plant can only sell its electricity to the host utility company, and the host utility company has an obligation to accept it at a rate of "avoided cost". This kind of avoided cost should include capacity and energy cost savings of the utility, and thus longterm marginal cost is a closer concept. Here, breakeven cost proposed in [4] is adopted as the "avoided cost" because it involves the effects of a BOT power plant on the long-term generation expansion planning of power system. Meanwhile, the host utility company dominates the electricity market where it sells all of electricity to end users at a price of "average cost". The relationship of a utility and a BOT power plant is illustrated in Figure 1. Here we simplify the scenario by assuming inelastic demands and free of uncertainties (some of which in fact can be taken into account in long-term generation expansion planning, such as demand uncertainty).

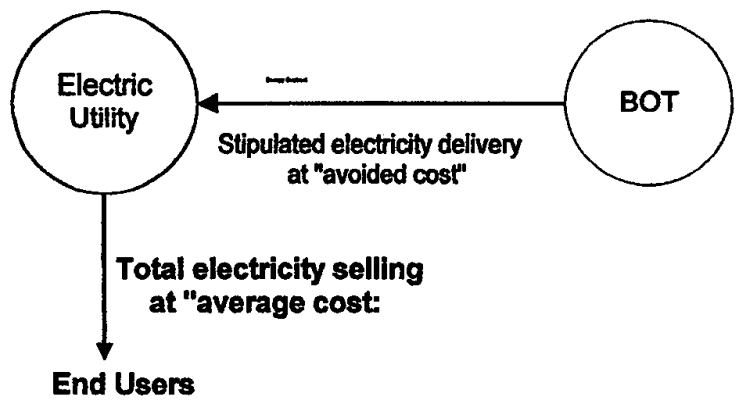

Figure 1 A Utility with a BOT Power Plant

This BOT arrangement can be modeled as a Stackelberg game that can be depicted as follows.

$\begin{array}{ll}\text { Notations: } \\ \mathrm{n} & \text { a year in horizon period } \\ \mathrm{N} & \text { horizon period of generation expansion planning } \\ \mathrm{D}^{\mathrm{n}} & \text { demand in year } \mathrm{n} \\ \mathrm{L}^{\mathrm{n}} & \text { peak load in year } \mathrm{n} \\ \mathrm{R}^{\mathrm{n}} & \text { system reserve in year } \mathrm{n} \\ Q_{B O T} & \text { minimal annual electricity delivery from the } \\ & \text { BOT power plant stipulated in the energy } \\ Q_{U}^{n} & \text { contract } \\ X_{U}^{n} & \text { total electricity supply of the utility in year } \mathrm{n}\end{array}$

$X_{B O T}^{n}$ accumulative capacity of the BOT power plant until year $\mathbf{n}$

$F C_{B O T}$ fixed investment cost of the BOT power plant

$V C_{B O T}$ variable cost of the BOT power plant

$F C_{U}^{n} \quad$ fixed investment cost of the utility in year $\mathrm{n}$

$V C_{U}^{n} \quad$ variable cost of the host utility in year $n$

$P_{B} \quad$ breakeven cost for BOT's electricity

$P_{A} \quad$ average cost of the host utility

$T_{B O T} \quad$ lifetime of the BOT power plant

$C_{0} \quad$ total cost of GEP without the BOT contract

$C_{B O T}$ total cost of GEP with the BOT contract

\section{Payoff function:}

Utility:

$f_{U}=\sum_{n=1}^{N}\left[D^{n} \cdot P_{A}-\left(F C_{U}^{n}+V C_{U}^{n} \bullet Q_{U}^{n}\right)\right]-N \bullet Q_{B O T} \bullet P_{B}(1)$

BOT:

$f_{B O T}=N \cdot Q_{B O T} \bullet P_{B}-\sum_{n=1}^{N}\left(F C_{B O T}^{n}+V C_{B O T}^{n} \bullet Q_{B O T}\right)$

Constraints:

(1) Energy balance

$$
D^{n}=Q_{B O T}+Q_{U}^{n} \quad n=1,2, \ldots, N
$$

For each year, the total amount of electricity generated by the BOT power plant and the host utility should be exactly equal to the total demands. Here, the detail operational scheduling is not taken into account in our model even though it is a tough problem.

(2) Capacity requirement

$$
X_{U}^{n}+X_{B O T}^{n} \geq L^{n}+R^{n} \quad n=1,2, \ldots, N
$$

In order to meet the demand in each year, adequate system capacity in each year is required, and can be installed by the BOT investor and the host utility. In addition, to maintain a certain degree of system security, a system reserve margin of capacity must be kept, which also should be burdened by both the BOT investor and the host utility.

(3) Other constraints

In many cases, there are bounds on investments for both, the BOT investor and the host utility, and sometimes these constraints will have big affects on decision progress of each player. Nevertheless, for simplicity, we didn't consider these factors in the paper. 
Definition of breakeven cost:

$$
P_{B}=\text { Breakeven } \cos t=\frac{C_{0}-C_{B O T}}{T_{B O T} Q_{B O T}}
$$

The breakeven cost implies that the host utility purchases the BOT's electricity in such a way that the utility's total generating cost in the horizon period of GEP should not change before and after the entry of the BOT power plant. Of course, the breakeven cost is the basic cost for the BOT power plant without a returned profit. Moreover the utility usually makes some changes referring to the breakeven cost according to corresponding policies in order to attract private investors.

With the game model at hand, the equilibrium $\left(Q_{B O T}{ }^{*}, P_{B}{ }^{*}\right)$ is our interest for the negotiating of the energy contract. In this game, Each player is concerned with the maximization of its benefit, that is, each one maximizes its payoff function under the constraints. From the first order of necessary conditions, each one should sell its electricity at its respective marginal cost. Moreover, the two objective functions can be combined into a global payoff function, and optimal social welfare will be abtained. In fact, the electricity transaction between the BOT power plant and the utility will be cancelled out in the global payoff function. However, usually in developing countries electric utilities price their electricity based on their average costs, but in order to encourage private investment, "avoided cost" pricing mechanism is adopted. This kind of asymmetric pricing phenomenon makes the problem complicated. Therefore, we transfer our game model to a two-level optimization problem for computing the equilibrium.

\section{A TWO-LEVEL OPTIMIZATION FORMULATION}

Both the utility and the BOT power plant in our game model will maximize their incomings. However, the utility must take BOT's electricity at its breakeven cost and sell all electricity to end users at its average cost. The BOT power plant can look for its maximum profit by adjusting its electricity output level under the breakeven cost pricing mechanism. So the game between a utility and a BOT power plant is a Stackelberg game.

A Stackelberg game is a dynamic game model in which a dominant (or leader) firm moves first and a subordinate (or follower) firm moves second. It is straightforward to extend what follows to allow for more than one following firm. Usually static Stackelberg problems can be treated as a class of multi-level optimization problems.

Even though our model is a Stackelberg model, the above price coupling mechanism is endogenous and requires the evaluation of both average and breakeven cost of the utility, so that common bilevel optimization techniques have difficulties to directly apply in the present problem. Therefore we restrict the equilibrium analysis of our model under the constraints of two existing pricing schemes, and formulate our game model as such a two-level optimization problem as follows:

Objective:

s.t.

GEP with buying BOT Electricity at breakeven cost

$$
\begin{array}{ll}
\max f_{B O T} & \\
D^{n}=Q_{B O T}+Q_{U}^{n} & n=1,2, \ldots, N \\
X_{U}^{n}+X_{B O T}^{n} \geq L^{n}+R^{n} & n=1,2, \ldots, N
\end{array}
$$

In our game model, the utility wants to maximize its net income by selling its electricity at average cost, thus it should behaves as if it just wants to minimize the total cost to satisfy the demand without any consideration about the electricity sale revenues. Therefore the long-term expansion planning is suitable for the utility to evaluate a BOT power plant, and a breakeven cost is calculated to price the electricity of a BOT power plant. The implementation of a long-term GEP with BOT electricity and the calculation of breakeven cost have been developed and discussed in our previous paper [4].

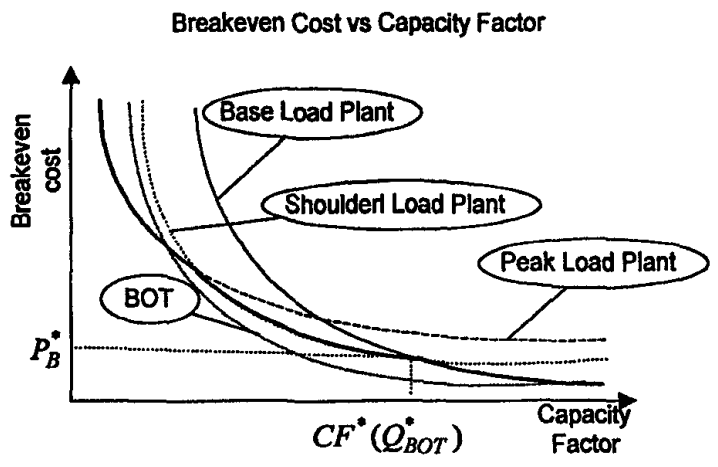

Figure 2 Breakeven Cost as a Function of Capacity Factor

To calculate the equilibrium $\left(Q_{B O T}{ }^{*}, P_{B}{ }^{*}\right)$, the relationship between $Q_{B O T}$ and $P_{B}$ should be examined. Let us look at a simple case where there are only three types of power plants existing and for future expansion, whose average cost curves are illustrated in Figure 2. The average cost of a plant is equal to its fixed (capital) cost per unit of energy production summed with its variable (operating) cost, and may be computed according to the following expression:

$$
\begin{aligned}
\text { average } \cos t & =\text { op } \cos t+\frac{\text { capital } \cos t}{\text { annual energy }} \\
& =\text { op } \cos t+\frac{\text { capital } \cos t}{\text { capacity factor } \cdot 8760}
\end{aligned}
$$

where opcost is the plant's operating cost, and capacity factor of BOT power plant stands for the percentage of its energy output with respect to its capacity. 
Furthermore it is assumed that the capacity of each type of power plant can be added continuously in GEP. Then it is easy to get the curve of breakeven cost vs capacity factor, i.e., the black curve in Figure 2. It can be explained that the breakeven cost will be equal to the average cost of peak load plants if the capacity factor of the BOT power plant is smaller, and equal to the average cost of base load plants if larger.

We further assume a BOT power plant is a shoulder load plant with cheaper fixed and variable cost than normal shoulder load plants, and its average cost is drawn in Figure 2. Then the equilibrium point is easy to find for this simple case, which is shown in Figure 2, and it can be proven that the equilibrium point is unique. Comparing with the slop of BOT curve, the slop of the breakeven cost curve, is smaller at the left of equilibrium point, and larger at the right. This property can be used as a criterion to search the equilibrium point. Of course, calculated by a practical GEP such as in [4], the curve of breakeven cost vs capacity factor will be much more complicated, but the shape of the curve should be similar.

\section{EOUILIBRIUM COMPUTATION}

Based on the above observation, an iterative algorithm for computing the equilibrium is developed.

For the master optimization problem, a long-term expansion planning which integrates BOT constraints is a suitable tool [4], which should give the breakeven cost in the meantime. For the slave optimization problem facing the BOT power plant, a Newton-like solution is used in our algorithm. For convenience and clarity, the annual energy of the BOT power plant is replaced by its capacity factor in the description of our algorithm.

Step 1:Set $\mathbf{i}=\mathbf{0}$.

Choose initial $C F_{B O T}^{0}$ to its biggest capacity factor (because a BOT power plant usually wants to generate energy as much as possible).

Step 2: For the given $C F_{B O T}^{i}$, calculate breakeven cost $P_{B}^{\prime}$ and its lefthand and righthand local derivatives, $S_{B}^{i^{-}}$and $S_{B}^{i^{+}}$with respect to $C F_{B O T}$ using the approach in [4].

Step 3: For the given $C F_{B O T}^{i}$, calculate the average cost $A C_{B O T}^{i}$ local derivative $S_{B O T}^{i}$ with respect to $C F_{B O T}$ on BOT average cost curve (which is first-order smooth).

Step 4: If $S_{B}^{i^{-}} \leq S_{B O T}^{i} \leq S_{B}^{i^{+}}$, stop.

Otherwise,

$$
\begin{aligned}
& \text { If } S_{B O T}^{i} \leq S_{B}^{i^{-}}, \\
& \qquad C F_{B O T}^{i+1}=C F_{B O T}^{i}-\left(\alpha+\mid P_{B}^{i}-A C_{B O T}^{i}\right)^{*}\left(S_{B}^{i^{-}}\right)^{-1} \\
& \text { Else, }
\end{aligned}
$$

$$
C F_{B O T}^{i+1}=C F_{B O T}^{\prime}+\left(\alpha+\mid P_{B}^{\prime}-A C_{B O T}^{\prime}\right)^{*}\left(S_{B}^{\prime+}\right)^{-1}
$$

$\alpha$ is a small number to prevent a zero value of $\mid P_{B}^{\prime}$ -

$A C_{B O T}^{l}$.

Step 5: Set $i=i+1$, go to step 2.

In the algorithm, lefthand and righthand local derivatives are approximately calculated by changing $C F_{B O T}$ at a time by a small amount and finding the new costs.

Usually a BOT power plant has lower fixed and variable costs due to its efficient management. So at the equilibrium point, $P_{B}^{*} \geq A C_{B O T}^{*}$. Even if $P_{B}^{*} \leq A C_{B O T}^{*}$, higher return rate or allowances from the host utility based on some policies, still will make a BOT investor benefit from a BOT project. The policy issues are outside of the scope of the paper.

\section{NUMERICAL EXAMPLES}

The proposed model and approach have been applied to an example system as described in [4]. The initial system, proposed plants and load data are listed in Table 1, 2 and 3, and a 20-year planning period is considered, which is divided into 5 time stages, each of four years duration.

Table 1 Existing plant (15 units)

\begin{tabular}{|l|l|l|}
\hline Plant Type & $\begin{array}{l}\text { Energy Cost } \\
(\$ / M W h)\end{array}$ & $\begin{array}{l}\text { Max Cap } \\
(\mathrm{MW} * \text { No) }\end{array}$ \\
\hline Oil \#1 (heavy oil) & 24 & $200 * 1$ \\
\hline Oil \#2 (heavy oil) & 27 & $200 * 1$ \\
\hline Oil \#3 (heavy oil) & 30 & $150 * 1$ \\
\hline LNG G/T \#1 & 43 & $50 * 3$ \\
\hline LNG C/C \#1 & 38 & $400 * 1$ \\
\hline LNG C/C \#2 & 40 & $400^{* 1}$ \\
\hline LNG C/C \#3 & 35 & $450 * 1$ \\
\hline Coal \#1 (anthracite) & 23 & $250 * 2$ \\
\hline Coal \#2 (bituminous) & 19 & $500 * 1$ \\
\hline Coal \#3 (bituminous) & 15 & $500 * 1$ \\
\hline Nuclear \#1 & 5 & $1000 * 1$ \\
\hline Nuclear \#2 & 5 & $1000 * 1$ \\
\hline
\end{tabular}

Table 2 Proposed generation plant (60 units)

\begin{tabular}{|c|l|l|l|l|}
\hline \multicolumn{2}{|l|}{ Plant Type } & $\begin{array}{l}\text { Energy Cost } \\
(\$ / M W h)\end{array}$ & $\begin{array}{l}\text { Capacity Cost } \\
(\$ / k W)\end{array}$ & $\begin{array}{l}\text { Max Cap } \\
(\mathrm{MW} * \text { No) }\end{array}$ \\
\hline 1 & $\begin{array}{l}\text { Nuclear } \\
\text { (PHWR) }\end{array}$ & 3 & 1750.0 & $700 * 3$ \\
\hline 2 & $\begin{array}{l}\text { Nuclear } \\
\text { (PWR) }\end{array}$ & 4 & 1625.0 & $1000 * 3$ \\
\hline 3 & Coal & 14 & 1062.5 & $500 * 18$ \\
\hline 4 & Oil & 21 & 812.5 & $200 * 18$ \\
\hline 5 & LNG C/C & 35 & 500.0 & $450 * 18$ \\
\hline
\end{tabular}

Table 3 Load duration curve

\begin{tabular}{|l|l|l|l|l|}
\hline Interval & $\begin{array}{l}\text { Peak load } \\
(\mathrm{MW})\end{array}$ & $\begin{array}{l}\text { Base load } \\
(\mathrm{MW})\end{array}$ & $\begin{array}{l}\mathrm{L}^{-1}(\mathbf{x})=(\mathrm{x}-\mathrm{d})^{2} / \mathrm{c} \\
\mathrm{c}^{*} 10^{3}\end{array} \mathrm{~d}^{*} 10^{3}$ \\
\hline Present & 5000 & 2500 & 0.285 & 5 \\
\hline
\end{tabular}

In the table 2, plant type 1 and 2 are base plants while 3,4 and 5 are shoulder and peak plants. The load duration curves are approximated with a second order function of loads. Peak loads and base loads are assumed to increase $10 \%$ per year. 
The reserve is $1 \%$. In addition, an annual discount rate of $10 \%$ for both capital and operating expenses are used.

In this example, a unit of type 5 is selected as a BOT power plant (peak load plant), which is introduced in the second stage, and whose capacity is $450 \mathrm{MW}$. Moreover, we assume its capacity cost is cheaper by $35 \%$ than the normal one of a same type of power plant, and its energy cost is same. Because breakeven cost just prices the basic cost the utility is willing to pay back to the BOT power plant, 35\% reduction of the energy cost of the BOT power plant is to make its payoff much positive in order to examine our model and approach.

Table 4 Breakeven Cost and Average Cost vs Capacity Factor of the BOT Power Plant

\begin{tabular}{|c|c|c|c|c|c|c|c|}
\hline $\begin{array}{c}\text { Capacity } \\
\text { factor }\end{array}$ & 0.05 & 0.1 & 0.15 & 0.2 & 0.25 & 0.3 & 0.35 \\
\hline $\begin{array}{c}P_{B} \\
(\$ / \mathrm{MWH})\end{array}$ & 53.91 & 32.49 & 25.36 & 21.64 & 19.13 & 17.27 & 15.9 \\
\hline $\begin{array}{c}A C_{B O T} \\
(\$ / \mathrm{MWH})\end{array}$ & 53.05 & 31.6 & 24.5 & 20.9 & 18.75 & 17.32 & 16.3 \\
\hline $\begin{array}{c}\text { BOT } \\
\text { payoff } \\
(\$ \mathrm{M})\end{array}$ & 2.712 & 5.613 & 8.199 & 9.46 & 5.992 & -0.79 & -8.8 \\
\hline
\end{tabular}

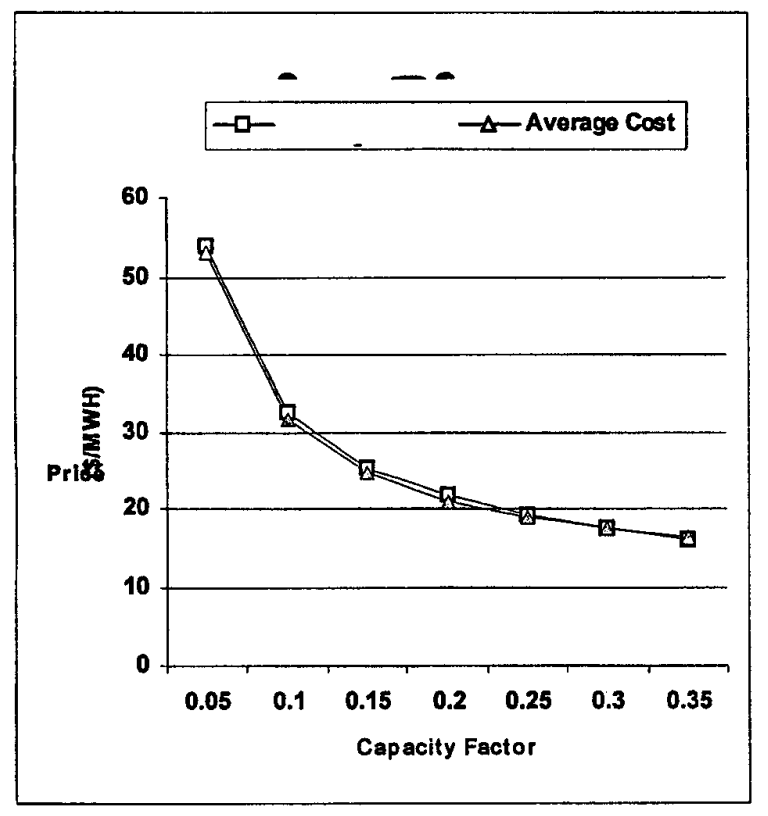

Figure 3 Breakeven Cost and Average Cost vs Capacity Factor of the BOT Power Plant

Using our game model and solution, the equilibrium is reached at $\left(C F_{B O T}{ }^{*}, P_{B}{ }^{*}\right)=(0.19,22.26)$. Some results during calculating the equilibrium point are shown in Table 4 and Figure 3 . In fact, in the long-term generation expansion planning the BOT power plant takes the place of a unit of type 5 in the original GEP without the BOT entry. However that unit has different capacity factors in different years, which range from 0.098 to 0.31 , meanwhile the annual capacity factors of the BOT power plant are fixed. This kind of nondispatchability presented by a BOT power plant causes many economic dispatch problems, and [12] discussed this issue and proposal some approaches to communicate the vale of dispatchability fro non-utility generation projects.

It has been shown that, the electricity price and fixed annul energy of a BOT power plant can be determined simultaneously in our game model, and the annul capacity factor of the BOT power plant is forced to go close to one of a same type of power plant in original GEP.

\section{CONCLUSIONS}

In this paper, we show how game theory can be used to evaluate a popular private power production: BOT arrangements. Using oligopoly theory, a Stackelberg game model between a BOT company and a utility is propsed, and which is applied to the negotiation and bargaining of a longterm energy contract. In our model, asymmetric pricing schemes of "avoided cost" and "average cost" are considered. To compute the equilibrium point of this Stackelberg game, it is transferred to a two-level optimization problem, and then is solved by an iterative algorithm. Finally our model and approach are demonstrated by being applied to a test system.

\section{ACKNOWLEDGMENTS}

The research is supported by a grant from the Research Grant Council of HKSAR.

\section{REFERENCES}

[1] C. Walker and A.J. Smith, Privatized infrastructure: the Build Operate Transfer approach, Thomas Telford, 1995.

[2] Yildiz Arikan, "Build Operate Transfer Model for New Power Plants for Turkey", Proceedings of 7th Mediterranean Electrotechonical Conference, 1994.

[3] Asian Development Bank, Technical Assistance to the People's Republic of China for the BOT CHANGSHA Power Project, Dec, 1996.

[4] Weiguo Xing and F.F. Wu, Cost-benefit Analysis of BOT Power Plants, Proceedings of IEEE PES Winter Meeting 2000, Singapore, Jan. 23-27, 2000.

[5] A.K. David, "Risk Modelling in Energy Contracts between Host Utilities and BOT Plant Investors", IEEE Trans. on Energy Conversion, vol. 11, no. 2, June 1996, pp. 359-366.

[6] Jukka Ruusunen, Harri Ehtamo and Raimo P. Hamalainen, Dynamic Cooperative Electricity Exchange in a Power Pool, IEEE Trans. on Systems, Man and Cybernetics, Vol. 21, No. 4, July/August, 1991, pp. 758-766.

[7] A. Haurie, R Loulou and G. Savard, A Two-Player Game Model of Power Cogeneration in New England, IEEE Trans. on Automatic Control, Vol. 37, No. 9, September 1992.

[8] Shams N. Siddiqi and Martin L. Baughman, Optimal Pricing of NonUtility Generated Electric Power, IEEE Trans, on Power System, Vol. 9, No. 1, February 1994.

[9] Akeo Kuwahara and Hiroshi Asano, Utility-Cogenerator Game for Pricing Power Sales and Wheeling Fees, IEEE Trans. on Power Systems. Vol. 9, No. 4, November 1994, pp. 1875-1879 
[10] J.D. Weber and T.J. Overbye, A Two-Level Optimization Problem for Analysis of Market Bidding Strategies", Proceedings of IEEE PES Winter Meeting 1999, New York, Jan. 31- Feb. 4, 1999.

[11] $H$. Singh(Ed.), IEEE Tutorial on Game Theory Applications in Electric Power Markets, IEEE PES Winter Meeting, New York, 1999.

[12] Douglas M. Logan, Jill S. Baylor and David Cotcher, Communicating the Value of Dispatchability for Non-Utility Generation Projects, IEEE Trans. on Power Systems, Vol. 10, No. 3, August 1995, pp. 1048-1413.

\section{BIOGRAPHIES}

Weiguo Xing received his BS and MS degrees from Tianjin University in 1991 and 1994 respectively. He is currently a Ph.D. student at Dept. of EEE, the University of Hong Kong. His research area is power system operation, power market, and power system investment planning.

Felix F. Wu (Fellow, IEEE) is currently Chair professor of Electrical Engineering in September 1995 and Pro-vice-chancellor at the University of Hong Kong. He has served as Professor and Vice Chairman, Department of Electrical Engineering and Computer Sciences, University of California, Berkeley, the same institute where he received his Ph.D. degree. Prof. Wu was elected as Fellow of IEEE in 1989. 